\title{
Bibliografía Médica Chilena: base de datos para autores chilenos
}

\author{
Alfredo Rioseco
}

Editor Bibliografía Médica Chilena

Sr Editor:

El año 2004 hacíamos ver (Rev. Médica Chile 2004; 132: 645) que, no existiendo una base de datos de referencias bibliográficas nacionales, los autores de artículos médicos publicados en revistas nacionales no incorporaban referencias bibliográficas chilenas a sus publicaciones, en detrimento del conocimiento de la experiencia nacional.

Para contribuir a subsanar lo anterior, se encuentra disponible en Internet, para médicos y alumnos de las escuelas de medicina, la página web Bibliografía Médica Chilena (www.bibliografiamedicachilena.cl) que ofrece acceso a 70.000 referencias bibliográficas de artículos publicados desde 1984 en revistas chilenas.

\section{El acceso a este portal es gratuito.}

De los 5.000 temas disponibles en esta base de datos, hemos seleccionado 700 como INDICE TEMÁTICO SELECT, que pueden ser requeridos a bibliografiamedicachilena@gmail.com.

Queda abierta, además, la opción de solicitar cualquier otro tema que no esté en la opción "SELECT" en la ventana de la página web: SOLICITUD TEMA ESPECÍFICO. Dado el gran volumen de información procesada, es muy posible que existan errores u omisiones que solicitamos disculpar, agradeciendo desde ya que nos informe para depurar este sitio, única base de datos de referencias bibliográficas médicas chilenas. 